\title{
THE ROLE OF NATIONAL AND INTERNATIONAL GEOSPATIAL DATA SOURCES IN THE MANAGEMENT OF NATURAL DISASTERS
}

\author{
A.KAYI, M.ERDOĞAN, A.YILMAZ \\ General Command of Mapping 06240 Dikimevi, Ankara, TURKEY (abdullah.kayi; mustafa.erdogan; \\ altan.yilmaz)@ hgk.msb.gov.tr
}

Commission VI, WG VI/4

KEY WORDS: Aerial Photographs, Orthopohoto, Satellite Imagery, Earthquake, Charter

\begin{abstract}
:
An earthquake occurred at Van City on 23 October 2011 at 13:41 local time. The magnitude, moment magnitude and depth of earthquake were respectively MI:6.7, Mw:7.0 and $19.07 \mathrm{~km}$. Van city centre and its surrounding villages were affected from this destructive earthquake. Many buildings were ruined and approximately 600 people died. Acquisition and use of geospatial data is very important and crucial for the management of such kind of natural disasters. In this paper, the role of national and international geospatial data in the management of Van earthquake is investigated.. With an international collaboration with Charter, pre and post-earthquake satellite images were acquired in 24 hours following the Earthquake. Also General Command of Mapping (GCM), the national mapping agency of Turkey, produced the high resolution multispectral orthophotos of the region. Charter presented the orthophotos through 26-28 October 2012. Just after the earthquake with a quick reaction, GCM made the flight planning of the $1296 \mathrm{~km}^{2}$ disaster area to acquire aerial photos. The aerial photos were acquired on 24 October 2012 (one day after the earthquake) by UltraCamX large format digital aerial camera. 152 images were taken with $30 \mathrm{~cm}$ ground sample distance (GSD) by $\% 30$ sidelap and $\% 60$ overlap. In the evening of same flight day, orthophotos were produced without ground control points by direct georeferencing and GCM supplied the orthophotos to the disaster management authorities. Also $45 \mathrm{~cm}$ GSD archive orthophotos, acquired in 2010, were used as a reference in order to find out the effects of the disaster.
\end{abstract}

The subjects written here do not represent the ideas of Turkish Armed Forces.

\section{INTRODUCTION}

Turkey is a tectonically active country that experiences frequent destructive earthquakes. The earliest recorded earthquake dates back to 411 B.C. There have been nearly 100 earthquakes with magnitudes 7.0 or greater in Turkey; and fourteen earthquakes with casualties of more than 10,000 have occurred since 342 A.D. Turkey's most severe earthquake in the $20^{\text {th }}$ century occurred in Erzincan on the night of December 28-29, 1939, leaving approximately 160,000 deaths behind.

Turkey lies on the Anatolian Plate. The plate was surrounded by the North Anatolian Fault and East Anatolian Faults. The country is an arena of collisions between the Eurasian Plate and both the African and Arabian Plates. These plates meet at the north of Turkey which is the most risky part of Turkey beginning from the vicinity of Kocaeli to the area north of Lake Van. This line is also named as North Anatolian Faultline.

The Van earthquake was a destructive magnitude $7.1 \mathrm{Mw}$ earthquake that struck eastern Turkey near the city of Van on 23 October 2011 at 13:41 local time. It occurred at a shallow depth of 20 kilometres. The earthquake and its aftershocks affected much of eastern Turkey, demolishing hundreds of buildings and burying numerous victims under the rubble. As of 2 November 2011, the affected area was still hit with continuous aftershocks of which count was over 1128 with magnitude greater than 3 (Figure 1).

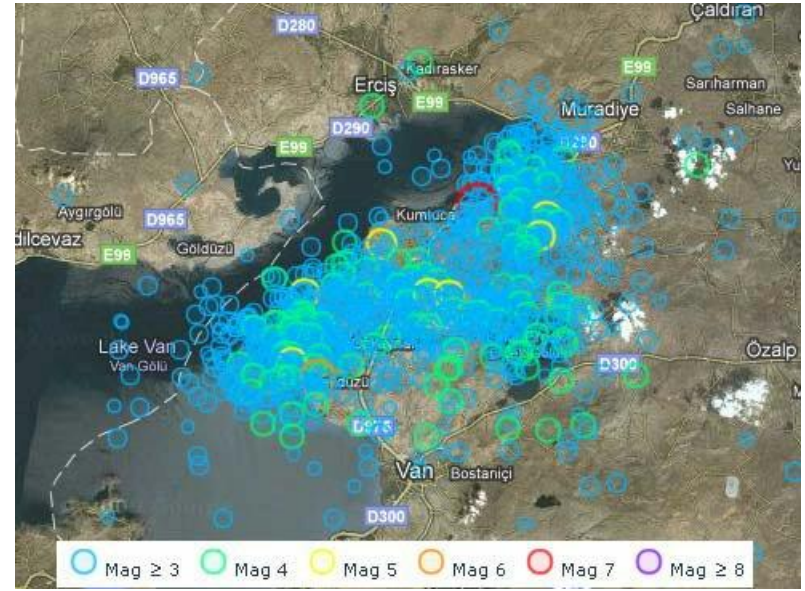

Figure 1. The distribution of 1128 aftershock earthquakes with $M>3$ as of $2^{\text {nd }}$ November 2011 (EMSC, 2011)

In such disasters, the role of geospatial data is very important. The usage of data can be divided to 3 phases: pre, during and post periods. Before the disasters, geospatial data is needed for the planning and analysis of the management of disaster. During the disaster, geospatial data is used to define the dimension and effect of disaster, planning and management of rescue and first aid works. After the disaster, the main role of geospatial data is the reconstruction of the affected region to recover the banes of disaster. 
In disaster management, there may be different organizations that are responsible for different duties and the coordination of them in a limited and stressful time is very important. So, generally authorities make their decisions based on their experience rather than information because of the limited time and data (Borkulo, 2005). For this reason, the rapid acquirement of reliable data is very important for the decision makers. GIS databases that contain disaster related information, can be combined with image data and this can allow the rapid assessment of disaster damage for more accurate decisions (Westen, 2000).

There are different definitions and approaches about disaster management. According to the definition made by UNDRO (1991) there are two phases that take place before a disaster occurs which are disaster prevention and disaster preparedness. Also there are three phases after the disaster that are disaster relief, rehabilitation and reconstruction. In all phases, geospatial data has a key role.

Just after that destructive Van earthquake, national and international geospatial data sources were used for the management of disaster and reconstruction of the region. In this paper, these national and international data sources, their acquirement process and use of them in the management of Van earthquake are investigated. In this context, Charter as an international geospatial data source to acquire satellite imagery and national efforts to acquire aerial imagery and orthophoto production are examined. The results and lessons learned from Van earthquake are summarized.

\section{INTERNATIONAL GEOSPATIAL DATA SOURCES}

There are many studies about the usage of imagery for damage mapping after disasters. These imageries vary from lowcost and uncalibrated airborne data (still or video imagery), deployed on balloons, kites, unmanned aerial vehicles or piloted aircraft, to sophisticated multi- or hyperspectral, lidar, thermal or radar devices mounted on air- or spaceborne platforms. Satellite systems are a good and fast option to use at such disasters anywhere in the world. For this purpose International Charter "Space and Major Disasters" was set up by the European, French and Canadian space agencies. The Charter is only responsible for the initial satellite image acquisition, while the subsequent data processing and damage mapping is mainly done by the DLR Center for Crisis Information (DLR-ZKI), UNOSAT, or the Service Régional de Traitement d'Image et de Télédétection (SERTIT, based at Strasbourg University, France). (Kerle, 2011). In Figure 2, data processed by DLR before and after Van Earthquake is shown. Also the member countries of Charter System is given in Figure 3.
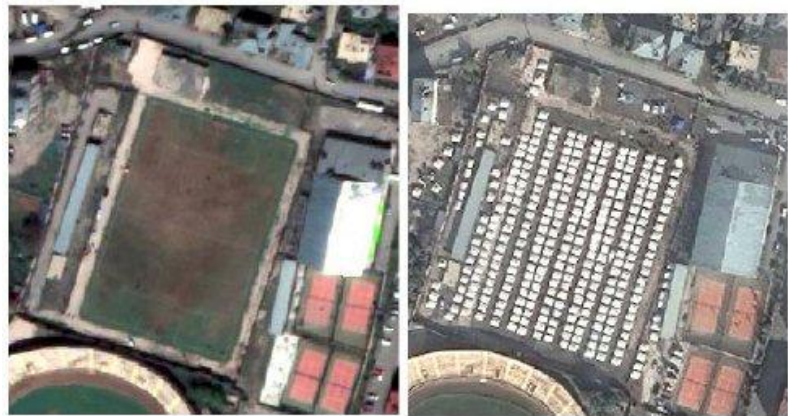

Figure 2: Tent Settlement in Ercis Before (left) and After (right) (DLR, 2011)

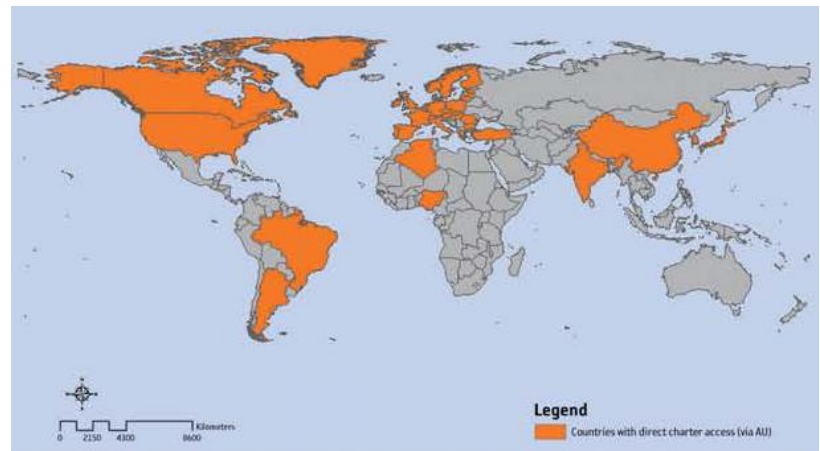

Figure 3: Charter Member Countries (Charter, 2014)

After Van Earthquake, Prime Ministry Disaster and Emergency Management Presidency (AFAD) as authorized user of Turkey to International Charter "Space and Major Disasters" has activated the system immediately and following intense collaboration with Charter, pre and post earthquake satellite images and their analysis were sent to the relevant authorities both in Van and Ankara.

At the first stage, satellite imageries with dates beginning from 06 May to 02 September 2011 were provided by Charter showing the earthquake affected area before the disaster. Following days, some more satellite imageries (Table 1) showing the after earthquake status were provided by Charter also.

Table 1. The post-earthquake imageries acquired from Charter

\begin{tabular}{|c|c|c|c|}
\hline $\begin{array}{l}\text { Satellite } \\
\text { Imagery }\end{array}$ & Resolution & Band & Date \\
\hline \multirow{2}{*}{ Quickbird-2 } & $0,6 \mathrm{~m}$ & PAN & \multirow{2}{*}{$\begin{array}{c}26-28 \\
\text { September } \\
2011\end{array}$} \\
\hline & $2,5 \mathrm{~m}$ & MS & \\
\hline \multirow{2}{*}{ Ikonos } & $1,0 \mathrm{~m}$ & PAN & \multirow{2}{*}{$\begin{array}{c}26-28 \\
\text { September } \\
2011\end{array}$} \\
\hline & $4,0 \mathrm{~m}$ & MS & \\
\hline
\end{tabular}

The first set of imagery was acquired at 26 October 2011. But unfortunately, the weather condition at this day was not good and there were cloud cover and fog over the imagery (Figure 4). It was very difficult to detect the ruined buildings from those imageries. For this reason another set of imagery were acquired by Charter at 28 October 2011 (Figure 5). Also, information about destroyed structures were extracted by DLR from acquired imageries after the earthquake and delivered to AFAD (AFAD, 2011). 


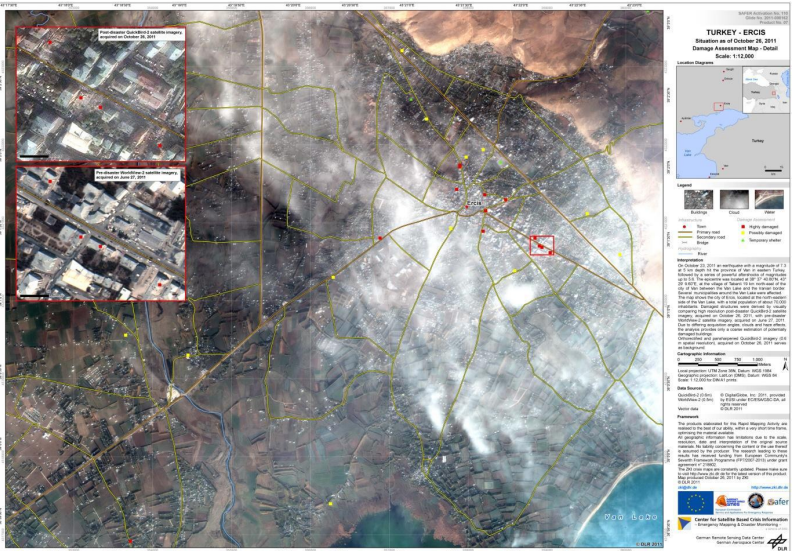

Figure 4. The post-earthquake (26 October 2011) imageries acquired from Charter (AFAD, 2011)

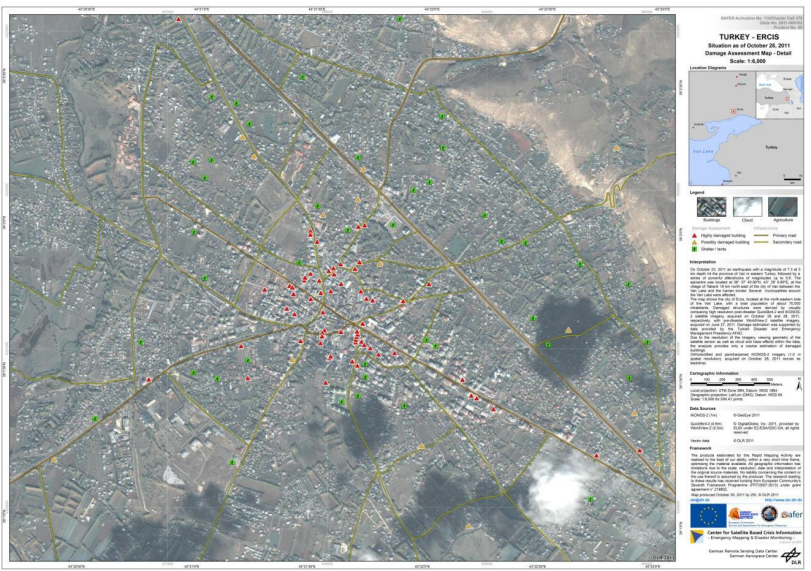

Figure 5. The post-earthquake (28 October 2011) imageries acquired from Charter (AFAD, 2011)

\section{NATINAL GEOSPATIAL DATA SOURCES}

Similarly to Charter, pre and post ortophotos of the disaster area were produced by General Command of Mapping (GCM) which is the national mapping agency of Turkey and located in Ankara. GCM have two airplanes (Beechcraft B200) and two large format digital aerial cameras (Microsoft Ultracam X and Eagle). Orthophotos produced in 2010 with the resolution of 45 $\mathrm{cm}$ were provided to AFAD a few hours after the earthquake. At the same time flight planning of the earthquake area (Figure 6) was done by GCM. The day after earthquake, which is 24 October 2011, one plane of GCM flew to Van which is approximately $1000 \mathrm{~km}$ far away from Ankara, 150 aerial imageries with $30 \mathrm{~cm}$ GSD were captured before noon and turn back to Ankara for processing of the imagery. The data processed and orthophotos were produced by directgeoreferencing in 3 hours. The produced orthophotos were provided to AFAD approximately at 08 pm 24 October 2014 nearly 1.5 day after the earthquake. The weather went to bad same day afternoon which blocks the acquirement of more aerial or satellite imagery. The area was again free of cloud 4 days after the earhquake.

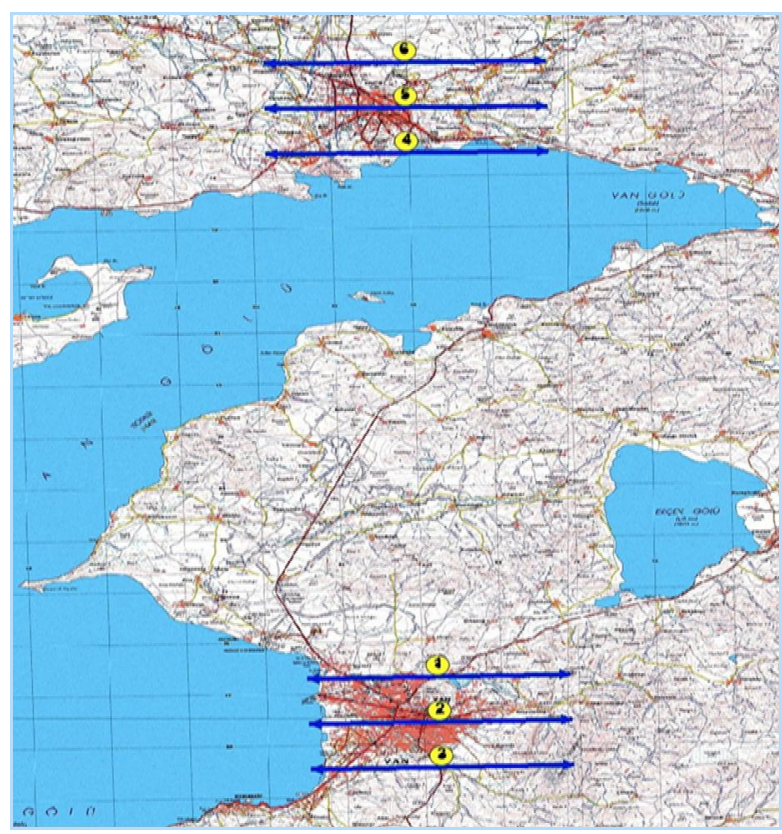

Figure 6. Flight planning of the disaster area

These orthopohotos benefits to damage assessment, the postdisaster rehabilitation and recovery activities. Those images (Figure 7) were provided by GCM very promptly and contributed to the planning and monitoring temporary settlement areas of tents and site selection activities. It also revealed the fact that very fast acquisition of those images will be very useful for also future events. (AFAD, 2011)

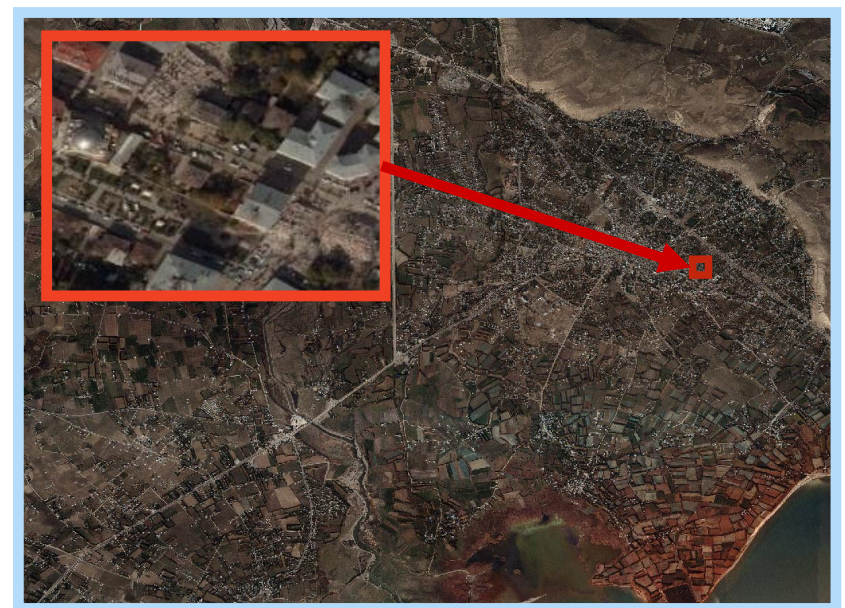

Figure 7. The post-earthquake (24 October 2011) imageries produced by GCM

These pre and post orthophotos were also used to detect the damaged buildings. Two damaged buildings can be easily seen in Figure 8 by comparing the pre and post orthophotos. By these analyses rescue works could be more accurately directed an managed by local authorities and the damage and needs of the region were analyzed more precisely by the central authoroties. 

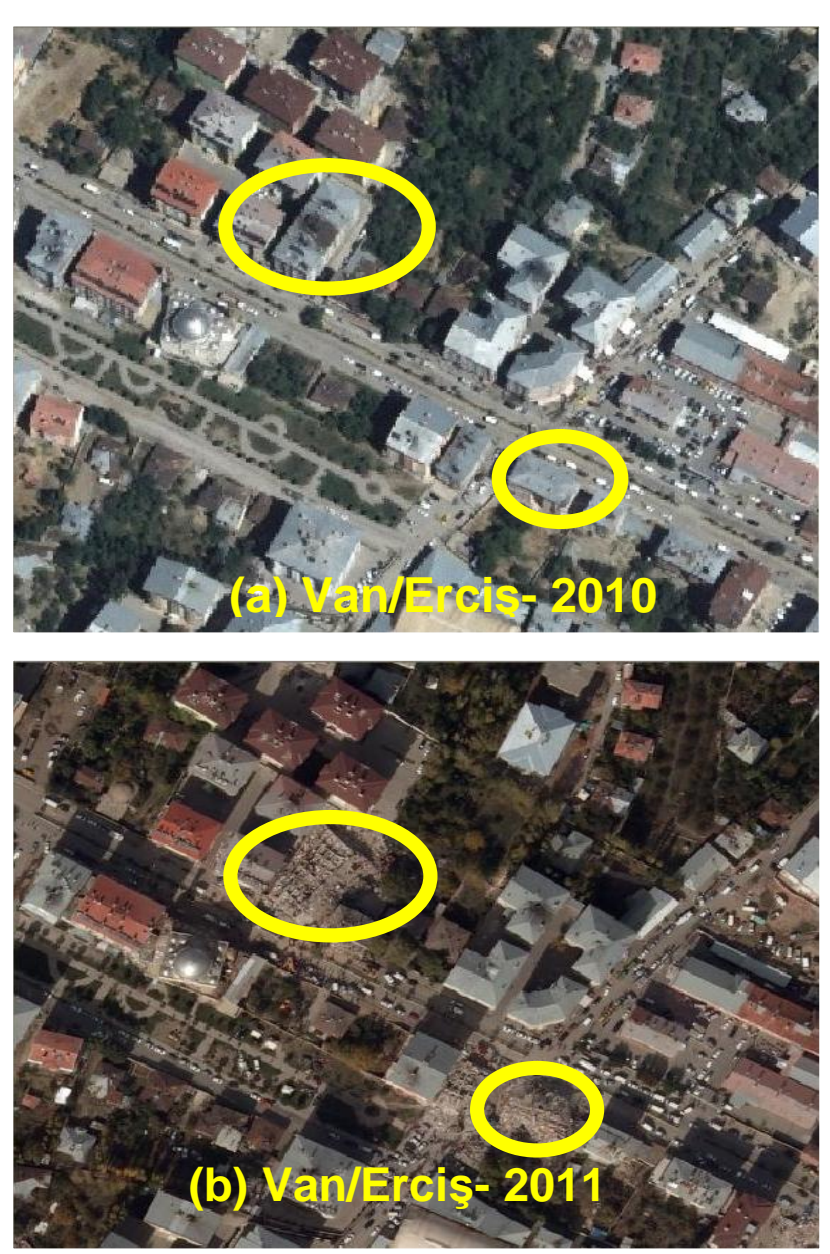

Figure 8. The pre (a) and post (b) earthquake orthophotos produced by GCM

At the following days of the earthquake AFAD requested imageries of some villages from GCM to determine real affect of disaster. GCM acquired and supplied imagery for these villages in 2 November 2011, but because of weather conditions Charter was unable to get imagery (AFAD, 2011). These aerial imageries were aided the management of the disaster such as monitoring the settled tent areas.

In Figure 9, the blue structures are the tents settled by AFAD in a small village.

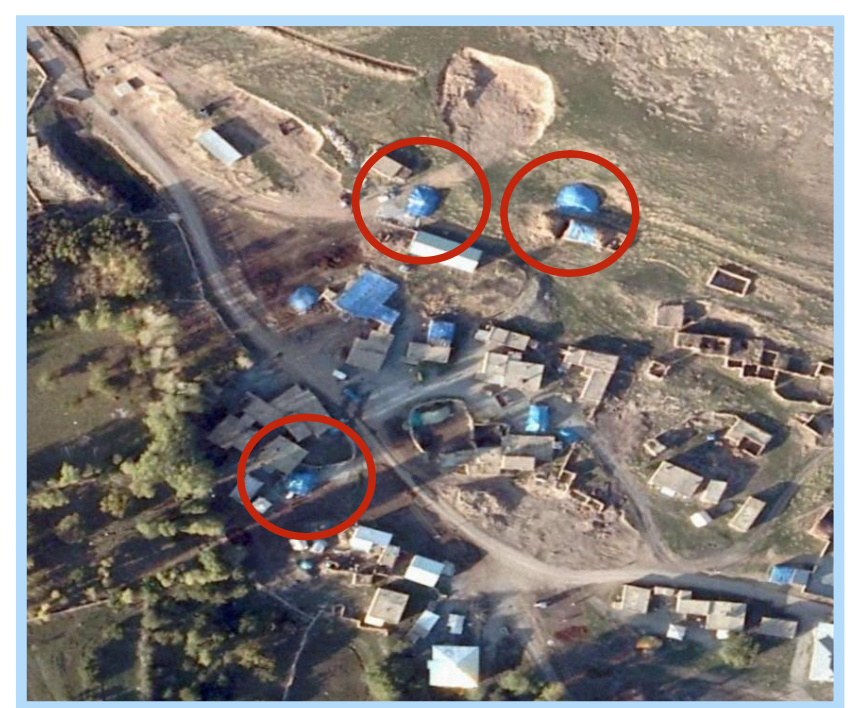

Figure 9. Settled tents in Tabanlı Village of Van.

\section{CONCLUSIONS}

Nowadays aerial and satellite imageries are widely used for disaster and emergency management, especially for damage assessment. These imageries also used for selection of temporary and permanent settlement, planning of infrastructure and restoration of the affected areas.

In Van earthquake case, the acquirement of first postearthquake satellite imageries from Charter is succeeded in 72 hours. But because of the cloud cover over the area, these imageries could not be benefited as planned. Another free of cloud imagery set could be acquired 5 days after the earthquake.

GCM acquired aerial imagery and served to authorities in 31 hours after the earthquake. Aerial imagery is a very good option to support the disaster management. Because of the orbital limitation of satellites, it can be difficult to acquire imagery in selected area and at selected time especially in bad weather conditions. Since aerial systems has no such orbit limitation according to the satellite systems, they can acquire imagery when the weather is appropriate.

In this earthquake, GCM processed the imagery in Ankara and it took some time to distribute this data to local authorities in Van. As a feedback from that event, GCM obtained a mobile photogrammetric system to be able to process all data on site. This system can decrease the time loss for transportation and distribution of data.

\section{REFERENCES}

AFAD, 2011, Van Earthquake Report, 2011. http://afad.gov.tr

Borkulo, E., Scholten, H.J., Zllatanova, S., Brink, A., 2005, Decision Making in Response and Relief Phases, Geoinformation for Disaster Management, First International Symposium on Geo-information for Disaster Management, March 2005, pp. 47-53.

Charter, 2014, Charter Universal Access Brochure. http://disasterscharter.org 
DLR, 2011, Damage Assessment Maps and Geographic Reference Maps, URL:http://www.zki.dlr.de/article/2135.

EMSC, 2011, EMSC, URL:http://www.emsccsem.org/Earthquake/202/Earthquake-M7-2-Eastern-Turkey)

Kerle, N., 2011, Remote Sensing Based Post-Disaster Damage Mapping - Ready for a Collaborative Approach?, URL: http://earthzine.org/2011/03/23/remote-sensing-based-post-

disaster-damage-mapping-ready-for-a-collaborative-approach/

UNDRO, 1991, Mitigating Natural Disasters. Phenomena, Effects and Options, United Nations Disaster Relief Co ordinator, United Nations, New York. 164 pp.

Westen, C., 2000, Remote Sensing For Natural Disaster Management, International Archives of Photogrammetry and Remote Sensing. Vol. XXXIII, Part B7. Amsterdam 2000. 